\title{
Inflammatory Maxillary Myofibroblastic Tumor: A Case Report
}

\author{
Khalfi Lahcen ${ }^{1 *}$, Chabi Wilfried ${ }^{2}$, N'Diaye Abibou ${ }^{3}$, Hamama Jalal ${ }^{1}$, Elkhatib Karim ${ }^{4}$ \\ ${ }^{1}$ Assistant Professor, ${ }^{2}$ Consultant Doctor, ${ }^{3}$ Resident Doctor, ${ }^{4}$ Professor (Head), Department of Stomatology and Maxillofacial Surgery, 'Mohammed V \\ Teaching Armed Forces Hospital, Rabat, Morocco
}

\author{
DOI: $10.36348 /$ sjmps.2020.v06i07.001 \\ | Received: 01.07.2020 | Accepted: 10.07.2020 | Published: 14.07.2020 \\ *Corresponding author: Khalfi Lahcen
}

\section{Abstract}

Inflammatory myofibroblast tumors (IMT) formerly known as inflammatory pseudotumours was first described in 1905 by Birch-Hirschfield and is characterized by myofibroblastic proliferation associated with lymphocytes, histiocytes, plasmocytes and macrophages that form part of a stroma rich in collagen fibres. Several hypotheses such as autoimmune, infectious and tumour origin have often been discussed, although etiopathogeny is not yet fully understood. The cervicofacial location is extremely rare, less than $3 \%$, and precisely the maxillary has been reported only twenty times in the literature .The treatment is based primarily on the most carcinogenic surgical resection possible when the tumor is accessible. We report the observation of a patient followed in our unit for a pseudoinflammatory maxillary localization tumor. The authors would like to share their approach and discuss the clinical, paraclinic and therapeutic aspects of this rare entity never seen before in our experience.

Keywords: Inflammatory myofibroblastic tumor, maxillary bone, oral.

Copyright @ 2020: This is an open-access article distributed under the terms of the Creative Commons Attribution license which permits unrestricted use, distribution, and reproduction in any medium for non-commercial use (NonCommercial, or CC-BY-NC) provided the original author and source are credited.

\section{INTRODUCTION}

Inflammatory myofibroblast tumors (IMT) formerly known as inflammatory pseudotumours are relatively rare anatomical and clinical entities. They are part of the differential diagnosis of malignant tumours and especially soft-part sarcomas with a very biting destructive potential $[1,2]$.

This pathology was first described in 1905 by Birch-Hirschfield and is characterized by myofibroblastic proliferation associated with lymphocytes, histiocytes, plasmocytes and macrophages that form part of a stroma rich in collagen fibres $[2,3]$. Several hypotheses such as autoimmune, infectious and tumour origin have often been discussed, although etiopathogeny is not yet fully understood $[1$, 4].

The literature review currently shows lung predominance, some cases of abdominal, retro peritoneal impairment, but very rarely a location of the cephalic extremity $[3,4,5]$. Their incidence in cervico- facial impairment is $15 \%$ and represents about $16 \%$ of the benign tumors in the oral cavity $[3,5]$.

The treatment of this condition is based primarily on the most carcinogenic surgical resection possible when the tumor is accessible [5].

We report the observation of a patient followed in our unit for a pseudoinflammatory maxillary localization tumor. The authors would like to share their approach and discuss the clinical, paraclinic and therapeutic aspects of this rare entity.

\section{ObServation}

A young woman 30-year-old, with no history of pathology, consulted for a small and isolated swelling of the left upper vestibule with inflammatory mucosal signs in a context of good general condition.

The orthopantomogram showed a subtotally toothless, a lytic image of the left maxillary accentuated in its posterior part. 


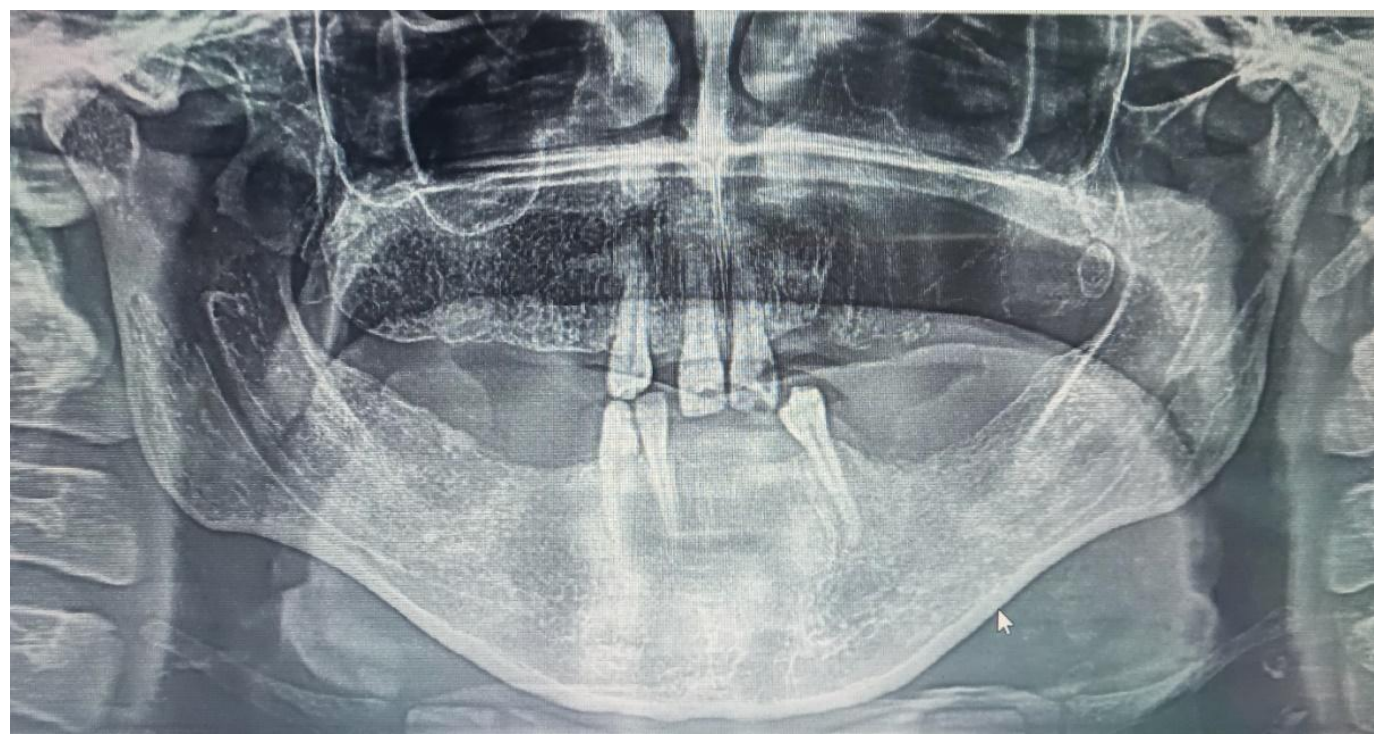

Fig-1: Showing left hemi-maxillary lytic image

The radiological assessment was supplemented by a maxillo facial CT which allowed us to better situate this osteolytic image centred on the left alveolar process of the maxillary, invading the bottom of the homolateral sinus, the bone palate, the vestibule and the soft parts of the cheek referring to a carcinoma or lymphoma.

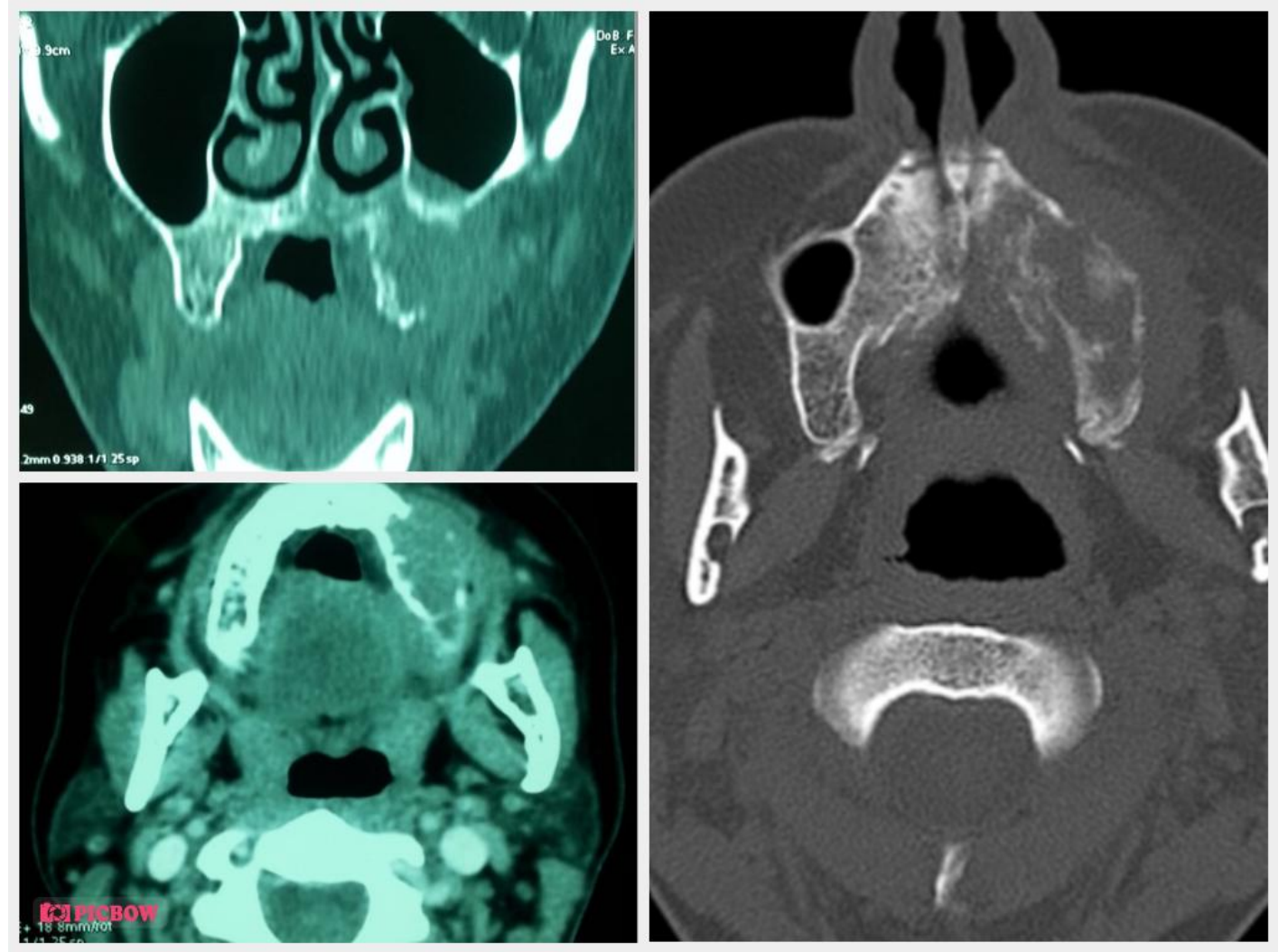

Fig-2: Maxillo facial CT showing the location and local extension of the tumour

Then we carried out a study of local and general extension, including nasofibroscopy and the computed-tomography cervico-thoraco abdominopelvian had all been returned without particularities.
Our patient was initially treated for 10 days with amoxicillin-Ac clavulanique and corticotherapy orally. The local signs were significantly reduced. A complete resection biopsy of the tumor was performed and the piece was addressed for histological study. The postoperative care was simple. 


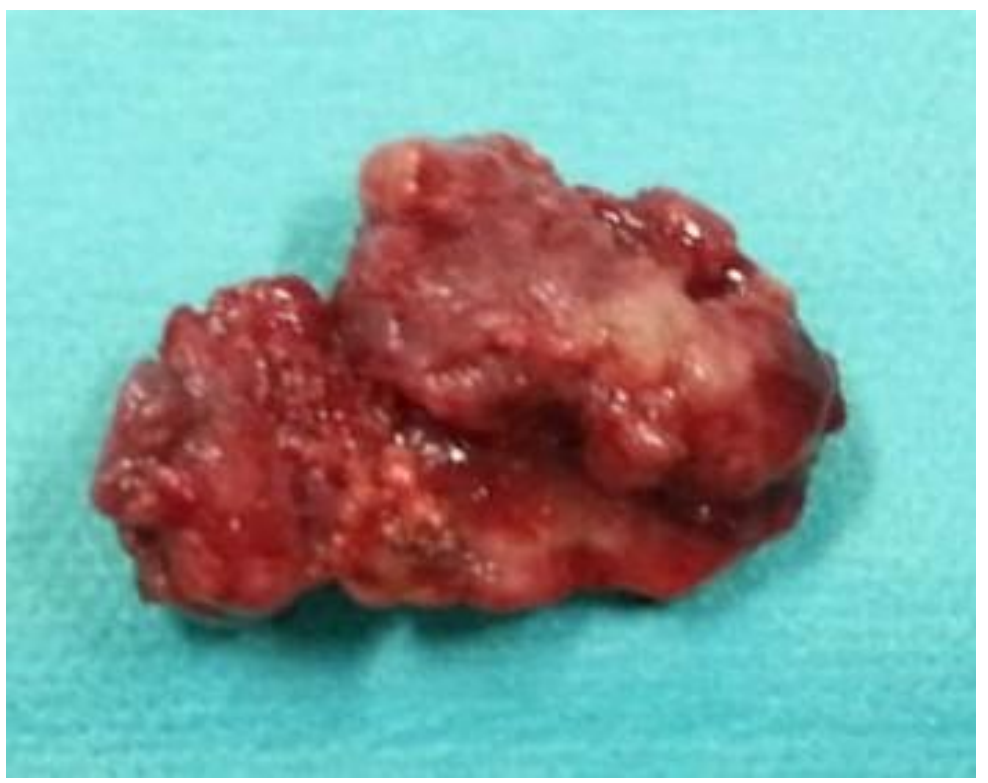

Fig-3: Resection tumor view

Histopathological study confirmed the presence of a connective tissue in a site of a polymorphic and non-specific inflammatory process. All this without any obvious histological evidence of tumor proliferation.

\section{DiscuSSION}

Inflammatory myofibroblast tumours (IMTs) are considered by WHO as intermediate neoplasia. Many localizations are reported in different organs and are more frequently diagnosed in the lungs, pancreas, mesentery and kidneys. The cervico-facial location is extremely rare, less than 3\%, and precisely the maxillary has been reported only twenty times in the literature [2, 6, 7]. Clinically, the IMTs of the maxillary, generally have no specificity. These are vestibular masses, or sinusian naso gradually developing over several months. This may progress to local inflammatory signs affecting locoregional dentistry, facial pain, epistaxis, nasal obstruction, deformations with infiltration of soft parts often suggestive of malignant tumour [5, 7, 8]. Nasal endoscopy may show edoema or enlargement of the mucosa and very rarely lymphadenopathy is found. In other cases, in particular visceral and pulmonary, there is generally an alteration of the general condition, with fever and consequent weight loss [7, 8]. Radiologically, CT and magnetic resonance imaging are the examinations that provide a better orientation of anatomical diagnosis compared to standard radiography or orthopantomogram. These are homogeneous tissue processes, with a fairly variable density accompanied by a remarkable bone lysis of the bone wall in front. These examinations also allow for the location of the locoregional extension of the tumor, particularly to the nasal cavity, palate, ptererygastric pit and orbit $[1,9]$. It may sometimes prove that these tumors are very vascularized, so angiography is required with a pre- surgical embolization gesture to anticipate possible uncontrollable hemorrhage during surgery. The radiological balance thus essential for diagnosis remains equally important in the post-therapeutic monitoring of the pathology $[1,5]$.

IMTs are classified as intermediate malignancy tumors with a local recidivism potential of $10-20 \%[6,8]$.

The macroscopic examination shows a generally well-circumscribed, non-encapsulated mass that infiltrates the various organs. Histologically, it is an alloy of fusiform cells that melts in a dense inflammatory infiltrate predominately mononuclear cells within a collagen myxoid stroma. Fusiform cells are medium-sized, starry or globular cells with large, vesicular nuclei with prominent eosinophilic nucleoli. The fusiform component is mesenchymal in nature and most often has the histological and immunohistochemical characteristics of myofibroblasts [1, 5, $10]$.

Non-infectious IMTs should be distinguished from specific infectious, particulary in relation to positive mycobacterial infections, observed in HIVpositive patients $[10,11]$.

It is also important to highlight the confusions that come from the various synonyms of this pathology:

- Plasma Cell Granuloma

- Inflammatory Pseudotumor

- Mastoid cellular Granulome

- Xantogranuloma

- Histocytome

- Inflammatory proliferation myofibroblastic or myofibrohistyocytoma 
Therefore, this diversity of the nomenclature sometimes leads to a division into histopathological subtypes [7].

IMTs also present a differential diagnosis with rhabdomyosarcomas, carcinomas, malignant mesenchymal tumors and lymphomas. They look like a malignant tumor and therefore require close monitoring. But thanks to the immune histochemical study we confirm the myofibroblastic phenotype of the cells that proliferate since they express smooth and focal muscle actin desmin, sometimes keratin AE1/AE3 in abdominal and bladder involvement. In $30 \%$ of cases, there is positivity for P80, corresponding to various translocations of the ALK gene with other genes. The IMTs are positive in $50 \%$ for ALK 1 in correlation with a rearrangement of the ALK gene $[3,12,13]$.
The management of these tumors is always poorly codified, and essentially consists of as complete a surgical removal as possible, while remaining the least mutilating $[14,15]$. Corticosteroid therapy sometimes used in cases of incomplete excision or recurrence has shown its limits in the treatment of these tumors. Similar to the anti-inflammatory radiotherapy used in patients who have resisted previous treatments, chemotherapy has not been effective $[6,16,17]$.

For our patient, surgical resection was carcinological, and clinical-radiological monitoring did not report recurrence with a six (06)-month decline. The patient has been reviewed annually for a clinical and radiological examination that is very satisfactory to date.

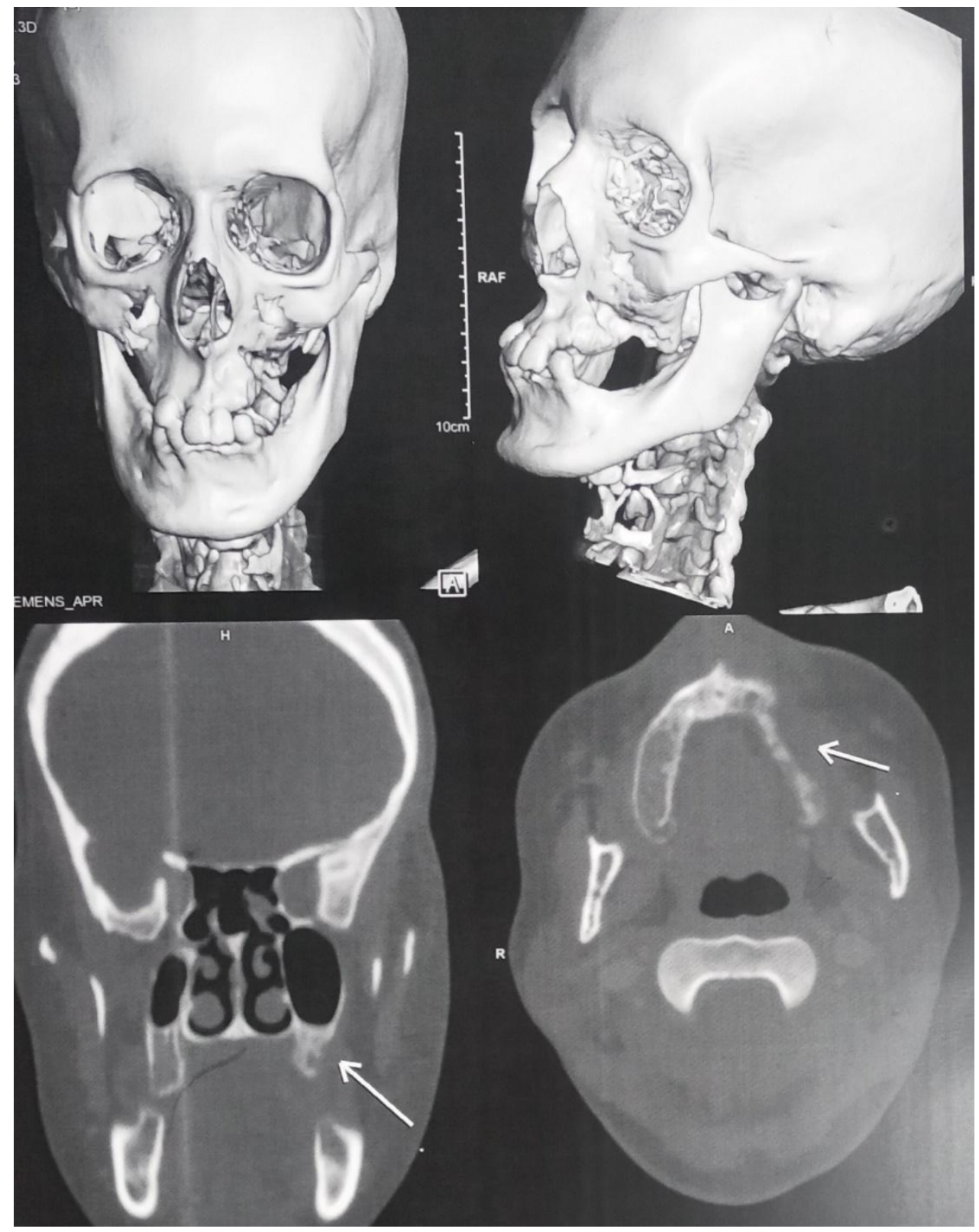


In maxillary disease, IMTs are a relatively rare entity and are characterised by a relatively favourable evolution compared to other locations where the risk of recurrence, malignant transformation, and metastatic power are rather high.

\section{Conclusion}

IMTs are relatively rare tumor group considered benign and whose etiology is still poorly understood. These tumors are characterized primarily by their clinical and radiological aggressive appearance, but also by their local expansion, which cause them to suspect a malignant process. Surgical removal remains the treatment of choice in maxillary damage, which in most cases allows complete remission. It is important to have a rigorous monitoring protocol for patients to detect recidivism or degeneration as early as possible.

\section{REFERENCES}

1. Gleason, B. C., \& Hornick, J. L. (2008). Inflammatory myofibroblastic tumours: where are we now?. Journal of clinical pathology, 61(4), 428-437.

2. Freeman, A., Geddes, N., Munson, P., Joseph, J., Ramani, P., Sandison, A., ... \& Parkinson, M. C. (2004). Anaplastic lymphoma kinase (ALK 1) staining and molecular analysis in inflammatory myofibroblastic tumours of the bladder: a preliminary clinicopathological study of nine cases and review of the literature.Modern Pathology, 17(7), 765-771.

3. Coffin, C. M., Watterson, J., Priest, J. R., \& Dehner, L. P. (1995). Extrapulmonary inflammatory myofibroblastic tumor (inflammatory pseudotumor) a clinicopathologic and immunohistochemical study of 84 cases. The American journal of surgical pathology, 19(8), 859-872.

4. Oudidi, A., Hachimi, H., Ridal, M., \& El Alami, M. N. (2006). Pseudotumeurs inflammatoires de la parotide. À propos d'un cas. La Lettre d'oto-rhinolaryngologie et de chirurgie cervico-faciale, (302), 20-21.

5. Ayachi, S., Moatemri, R., Mziou, Z., Oualha, L., Mestiri, S., \& Khochtali, H. (2015). Pseudotumeur inflammatoire $\mathrm{du}$ sinus maxillaire: un cas. Médecine Buccale Chirurgie Buccale, 21(3), 157-162.

6. El Khatib, K., Guerrouani, A., Hajji, F., Sabani, H., Al Bouzidi, A., \& Rzin, A. (2011). Tumeurs bénignes de la cavité buccale: étude rétrospective de 209 cas. Médecine Buccale Chirurgie
Buccale, 17(2), 115-119.

7. Coffin, C. M., Humphrey, P. A., \& Dehner, L. P. (1998, May). Extrapulmonary inflammatory myofibroblastic tumor: a clinical and pathological survey. In Seminars in diagnostic pathology. 15(2):85-101.

8. Lazaridou, M., Dimitrakopoulos, I., Tilaveridis, I., Iordanidis, F., \& Kontos, K. (2014). Inflammatory myofibroblastic tumour of the maxillary sinus and the oral cavity. Oral and maxillofacial surgery, 18(1), 111-114.

9. Marraoui, W., Jean, B., Muheish, M., Trouillier, S., Kemeny, J. L., \& Dorcier, F. (2012). Imaging of inflammatory myofibroblastic cervical tumours: a case report. Diagnostic and Interventional Imaging, 93(7-8), 617-620.

10. Chan, J. K., Cheuk, W., \& Shimizu, M. (2001). Anaplastic lymphoma kinase expression in inflammatory pseudotumors. The American journal of surgical pathology, 25(6), 761-768.

11. Park, S. B., Lee, J. H., \& Weon, Y. C. (2009). Imaging findings of head and neck inflammatory pseudotumor. American Journal of Roentgenology, 193(4), 1180-1186.

12. Maruya, S. I., Miura, K., Tada, Y. I., Masubuchi, T., Nakamura, N., Fushimi, C., ... \& Kamata, S. E. (2010). Inflammatory pseudotumor of the parapharyngeal space: a case report. Auris Nasus Larynx, 37(3), 397-400.

13. Lawrence, B., Perez-Atayde, A., Hibbard, M. K., Rubin, B. P., Dal Cin, P., Pinkus, J. L., ... \& Fletcher, J. A. (2000). TPM3-ALK and TPM4ALK oncogenes in inflammatory myofibroblastic tumors. The American journal of pathology, 157(2), 377-384.

14. Gleizal, A., Ranchere-Vince, C., \& Beziat, J. L. (2007). Inflammatory myofibroblastic tumour of the tongue: a case report. British Journal of Oral and Maxillofacial Surgery, 45(5), 423-424.

15. Lai, V., Wong, Y. C., Lam, W. Y., Tsui, W. C., \& Luk, S. H. (2007). Inflammatory myofibroblastic tumor of the nasal cavity. American journal of neuroradiology, 28(1), 135-137.

16. Gale, N., Zidar, N., Podboj, J., Volavšek, M., \& Luzar, B. (2003). Inflammatory myofibroblastic tumour of paranasal sinuses with fatal outcome: reactive lesion or tumour?. Journal of Clinical Pathology, 56(9), 715-717.

17. 周水洪, 阮凌翔, 徐盈盈, 汪审清, 任国平, \& 凌 玲. (2004). Inflammatory myofibroblastic tumour in the left maxillary sinus: a case report. 中华医学 杂志: 英文版, 117(10), 1597-1599. 